\title{
Educação para Ciência, Tecnologia, Engenharia e Matemática e as Relações com a Politica de Avaliação em Larga Escala na Educação Básica*
}

\author{
STEM Education Plan and the Relationships with the The Large Scale \\ Assessment Policy
}

\author{
Veronica Gesser** \\ Universidade do Vale do Itajaí \\ Lilia DiBello*** \\ Barry University
}

Resumo Neste artigo tivemos a intenção de caracterizar as relaçôes existentes entre o Plano STEM estadunidense e as políticas de avaliação para a Educação Básica no Estado da Flórida. Trata-se, portanto, de uma pesquisa cujos dados foram coletados nos documentos oficiais dos Estados Unidos e do Estado da Florida disponíveis online. Empregamos a análise de conteúdo como técnica no sentido de caracterizar o nível de correspondência, influencias e de relaçóes entre os documentos oficiais de ambas as entidades. As relaçóes que observamos por meio dos termos padronização, mensuração, treinamento, modelos, habilidades, áreas prioritárias, desempenho/ progresso e desenvolvimento/crescimento profissional, neste caso, é o de alinhamento, de nivelamento de valores, de imaginários e de verdades determinadas por interesses de alguém ou de determinados grupos hegemônicos e que estão sendo legitimados pelo Estado.

PALAVRAS-CHAVE: Educação para STEM; Avaliação educacional;

Currículo; Políticas publicas.

Abstract In this article we characterize the relationship between STEM Education policy of the United States, and the evaluation policies for basic education in the State of Florida. An analysis of data collected from official documents available online was conducted. We employed the technique of content analysis in order to characterize the level of correspondence, influences and relationships between the official documents of both entities. We identified relationships which were observed through the terms standardization, measurement, training, models, skills, priority areas, performance/progress and development/professional growth. These alignments between the federal policy level and the impact on practice at the State level highlight certain truths and areas where perhaps imaginary interests of certain hegemonic groups are being legitimized by the State.

KEYWORDS: STEM Education; Educational assessment; Curriculum, and Public policy. 


\section{Introdução}

Preparar estudantes com habilidades para a nova economia implica, de acordo com o Presidente Americano Barack Obama, focar em solução de problemas, pensamento critico, Ciência, Tecnologia, Engenharia e Matemática. Algumas dessas mudanças são difíceis, mas valiosas, argumenta. (STEM, 2013). Esta afirmação nos faz lembrar de que as transformações ocorridas nas últimas três décadas têm sido muito aceleradas e, ao mesmo tempo, muito voláteis e pouco previsíveis. No entanto, essas transformações não são resultantes da educação, em grande parte. Ao contrário, o desenvolvimento tecnológico avançado decorrente dos interesses econômicos e políticos, além de agendas globais é o que vem produzindo transformações de longo alcance no âmbito da educação em todas as modalidades educativas do contexto mundial. (BALL, 2012).

Ao longo dos últimos anos vimos a realização de pesquisas sobre as políticas públicas de currículo e de avaliação no âmbito da educação básica e da educação superior. Estas investigações vêm apontando dados relevantes para a compreensão dos contextos e de instituições em que as agendas para a definição e elaboração dos textos das políticas públicas de currículo e de avaliação são produzidas. A questão das políticas públicas educacionais, hoje, lida com um contexto extremamente complexo. Isso parece ser preocupação crescente por parte dos governos, instituições públicas e privadas em âmbito mundial. (UNESCO, 1990).

O século XXI, caracteristicamente, vem sendo permeado por crescentes transformações, queda de paradigmas, desvelamento de novas tecnologias, novas exigências no mundo do trabalho, o que tem exigido dos profissionais de diversas áreas incessante aperfeiçoamento e atualização. Portanto, nesse cenário, dependendo dos princípios fundantes das políticas públicas, isso pode tanto ser potencializado como pode ser também dirigido intencionalmente, para fins ideologizantes já predeterminados, pois os currículos escolares se constituem como fortes produtores de subjetividades, de imaginários e, da mesma forma, as políticas de avaliação podem servir como ferramentas determinantes para esse processo formativo. (SPOSATI, 2011).

Tomaremos como premissa o fato de que as políticas de avaliação em larga escala, para fins de acompanhar a qualidade do desempenho dos estudantes, a competência dos professores, a eficiência dos cursos de formação de professores, a eficiência dos gestores escolares e a eficácia de seus sistemas educacionais, têm exercido papel preponderante na determinação do que será ensinado, como será ensinado, para que e para quem serão os conteúdos e condutas escolares (SANTOS, 2008); ou seja, as politicas de avaliação têm funcionado como ferramenta intencional na definição e massificação dos currículos escolares no contexto global.

Aqui situamos nossa problemática - qual a real intenção de um país como os Estados Unidos na determinação de um plano estratégico para que a Educação Básica foque prioritariamente em Ciências, Tecnologia, Engenharia e Matemática. Curiosamente, subsequente a este Plano (STEM), por que a maioria dos Estados Americanos alteram os seus instrumentos de avaliação em larga escala para a avaliação 
da Educação Básica, incluindo a Florida, estado onde realizamos esta investigação. Que impactos ou influencia o Plano STEM poderá ter em outros países, particularmente em países menos desenvolvidos, como o Brasil, por exemplo. Ao tomar essas questões como norteadores, nossa intenção neste artigo é a de caracterizar as relações existentes entre a política estratégica para o desenvolvimento dos Estados Unidos, o STEM - Science, thecnology, Engeneering, and Mathematics Education: 5-Year strategic plan $^{1}$, e a politica de avaliação para a educação básica no estado da Florida ${ }^{2}$, visando apontar seus impactos na determinação do currículo escolar deste mesmo estado, bem como seus efeitos potenciais para as políticas de currículo e de avaliação em esfera Global.

\section{Metodologia}

Nas descobertas fecundas em ampliar referenciais teóricos e práticos na arte de compreender, conhecer e prospectar, como explica Serres (1996, p. 35) "depressa se impõe a necessidade de construir uma jangada, ou um barco, mesmo uma ilha, sólidas e consistentes, e os dotar de instrumentos, objetos, abrigos e de povoar os personagens". Consideramos que este recorte, o qual vamos analisar como um processo, como um olhar entre outros múltiplos possíveis, convergentes ou contraditórios, como um episódio e, como tal inclui imprevisibilidade, possibilidade, emergência e/ou como um vir a ser, poderá servir para construirmos novas conjecturas e olhares prospectivos em relação às políticas públicas educacionais mundiais, nacionais e locais.

Por isso, a necessidade de mediações e de análises, neste artigo, alude ao que Chauí (1988, p. 33) expressa sobre o olhar. Nossa crença está na visão de que o olhar se faz em nós pelo exterior e, simultaneamente, se faz de nós para o exterior. "[...] o olhar é, ao mesmo tempo, sair de si e trazer o mundo para dentro de si." Portanto, nesta perspectiva, o processo de conhecer é o de clarear a vista como se o saber nos permitisse, enfim, olhar.

Nosso interesse é o de olhar para vermos e analisarmos sob diferentes perspectivas e referenciais, pois conforme Merleau-Ponty (2007, p. 78), "ver é ter à distância [...] o próprio olhar é a incorporação do vidente no visível, busca dele próprio, que está no visível". Este se desdobra em deslocamentos, em afastamentos necessários às novas direções para alcançar os olhos em diferentes camadas, superfícies e entranhas. Cardoso (1988, p. 349) contribui para expressarmos que aqui "o olho não descansa sobre a paisagem contínua de um espaço inteiramente articulado, mas se enreda nos interstícios de extensões descontínuas, desconcertadas pelo estranhamento." Diante disso, provoca a abertura de diferente ou de novos espaços, rompendo com a superfície lisa e luminosa antes oferecida à visão e assim, podendo alcançar lugares, perspectivas e zonas mais claras. Para tal, empregamos a análise de conteúdo como técnica no sentido de caracterizar o nível de correspondência, influências e de relações encontradas entre os documentos oficiais de ambas as entidades, ou seja, o Plano STEM e os textos das politicas de avaliação da Educação Básica do Estado da Florida, ambos disponíveis on line. Tomamos como base inicial o fato de que as políticas de avaliação em larga escala vêm exercendo função determinante na definição e massificação dos currículos escolares no contexto global e, neste caso, em particular. 
Os documentos analisados consistem em um conjunto de textos oficiais das entidades já indicadas a partir dos quais fizemos um olhar exotópico ${ }^{3}$. Consideramos que nossa parceria, neste projeto, se constitui como condição ímpar para esse movimento. Consideramos que o distanciamento em relação às próprias produções e aos referenciais teóricos de base com os quais vimos trabalhando, o assumir posição exotópica em relação ao já dito, vem se constituindo como momentum, condição de possibilidades para a formação de diferentes e/ou novos diálogos na interface das relações entre políticas públicas, currículo e avaliação.

\section{O Plano Federal para Educação em Science, Thecnology, Engeneering e Mathematics (STÉM): Plano Estratégico para 5-Anos.}

De acordo com Plano STEM (2013, p. vi), para que os Estados Unidos mantenha sua posição de destaque mundial será preciso [...] que o país continue sua liderança em Ciência, Tecnologia, Engenharia e Matemática [...]. No entanto, o Plano STEM (2013, p. vi) apresenta levantamentos realizados por várias de suas subcomissões (CoSTEM) as quais alertam para "[...] evidência de que os atuais caminhos educacionais não estão conduzindo para uma força de trabalho suficientemente ampla e bem treinada para atingir este objetivo".

Portanto, de acordo com o Plano STEM (2013, pp. vi-vii), investir em educação para Ciência, Tecnologia, Engenharia e Matemática é fundamental para o futuro dos Estados Unidos e sua economia, pelas seguintes razões: a) os postos de trabalho do futuro serão trabalhos voltados a STEM; b) o sistema educacional da Educação Básica Americana está abaixo da média dos 33 países que fazem parte da OCDE (Organization for Economic Cooperation and Development) que recentemente participaram do estudo PISA (Programme for International Student Assessment). Doze (12) desses países têm melhores scores que os Estados Unidos em Ciências e 17 deles têm melhores scores em matemática; c) progresso em relação ao Plano STEM é critico no sentido de construir uma sociedade justa e inclusiva, pois as estatísticas levantadas mostram que o desempenho e a participação de mulheres e de outras minorias em Ciência, Tecnologia, Engenharia e Matemática é significativamente preocupante porque apresentam índices de representação substancialmente baixos nessas áreas.

Além destes principais motivos encontrados no Plano STEM (2013), os Estados Unidos pretendem investir três bilhões de dólares anuais na Educação para essas áreas, desde o Jardim de Infância até a Pós-Graduação, além de ambientes educacionais não formais. Ao total, são 14 CoSTEM's federais envolvidas e outras agências públicas, privadas e instituições não governamentais. Muitos programas e investimentos vêm sendo criados para providenciar recursos de aprendizagem para o público em geral, incluindo "[...] publicações, web sites, programas televisivos, exibições em museus, programas complementares para além dos horários escolares e recursos midiáticos, entre outros". (STEM, 2013, p. 4). Por meio deste plano e por meio de esforços de agências federais e de agências parceiras já existentes,

[...] a intenção é a de atingir significantes e mensuráveis impactos em cinco pontos prioritários de investimento para a educaçáo em STEM: 
1) melhorar o ensino de STEM da Educação Básica (P-12); 2) aumentar e sustentar o envolvimento do público e da juventude em STEM; 3) melhorar os programas educacionais de graduação em STEM; 4) melhor servir aos grupos historicamente mal representados em áreas de STEM e; 5) criar programas de pós-graduação para a força de trabalho atual em STEM." (STEM, 2013, p. 8, tradução nossa).

Para o alcance do primeiro ponto prioritário o plano STEM (2013, pp. 9-11) tem como meta a formação de 100.000 "excelentes" novos professores para a Educação Básica até 2020, além de suporte para os atuais professores. Em relação ao segundo ponto, a meta é aumentar em $50 \%$ o suporte para os jovens que demonstrarem experiência efetiva e autêntica em relação a habilidades em STEM em cada ano anterior a sua formação no Ensino Médio. Já para o terceiro ponto a meta é a de graduar um milhão adicional de estudantes em STEM durante os próximos 10 anos. Em relação à meta quatro, o plano tem como objetivo um aumento significativo de mulheres e de outras minorias ainda mal representadas na força de trabalho em STEM para os próximos 10 anos. E, por fim, para o quinto ponto prioritário o plano prevê investimento na criação de programas de pós-graduação stricto sensu em STEM, visando profissionais com expertise em pesquisa básica e aplicada, além de opções em formação com habilidades especializadas em de áreas de importância nacional e habilidades necessárias para o sucesso em uma larga escala de carreiras.

Segundo o próprio plano, a implementação dessas metas serão realizadas basicamente por meio de duas grandes abordagens: 1) Construir novos modelos para alavancagem de patrimônio e expertise. Esta abordagem envolveria “[...] implementar um conceito de liderança e agências colaboradoras em áreas prioritárias para alavancar capacidades entre agências para garantir o impacto mais significativo dos investimentos federais na educação em STEM.” (STEM, 2013, p.13); 2) Construir e usar abordagens baseadas em evidências. Para esta abordagem se faria necessário "Realizar pesquisa em educação para STEM e avaliação para construir evidências sobre práticas promissoras e eficácia do programa", de maneira que pudessem ser usadas [...] entre as agências e compartilhar com o público para melhorar o impacto do investimento Federal em educação para STEM". (STEM, 2013, p. 14).

Por fim, na sequência do trabalho que será feito dentro das convocatórias iniciais em torno das áreas prioritárias, os 14 CoSTEM's criarão subcomissões de implementação do plano STEM em relação às áreas prioritárias de investimento e abordagens de coordenação entre agências, conforme o caso. As subcomissões de implementação seriam responsáveis por tarefas, como: revisão de roteiros e planos de implementação elaborados pela liderança inicial e agências colaboradoras; acompanhamento da implementação das áreas prioritárias de investimento da educação no âmbito do Plano Estratégico; desenvolvimento e monitoramento de métricas para o progresso, avaliando se as eficiências e maior impacto estariam sendo alcançados, recomendando ajustes no processo de implementação, se for o caso; e, desenvolvimento de uma estrutura e um processo de planejamento orçamentário Federal mais coordenada em relação às metas da educação para STEM. (STEM, 2013, p. 14-15). 


\section{Política de Avaliação em Larga Escala do Estado da Florida}

De acordo com o Departamento de Educação da Florida, os estudantes da Educação Básica, a partir do ano acadêmico de 2014-2015, vêm se submetendo a um novo modelo de avaliação de desempenho escolar denominado "Florida Standards Assessments (FSA)" o qual está disponível on line, conforme já indicado no início deste trabalho. Os novos testes que compõem o FSA têm como objetivos "[...] ajudar no sucesso dos padrões educacionais da Florida". O FSA inclui alguns testes: o ELA (English Language Arts), Mathematics (Matematica) e o end-of-course (EOC) subjects - matérias de final de curso como Álgebra 1, Álgebra 2 e Geometria. Estes testes [...] irão servir aos estudantes da Florida ao mensurar seus ganhos e progressos educacionais". Além disso, os estudantes, pais e/ou responsáveis e educadores são "[...] motivados em ficar conectados no portal do FSA para receber importantes anúncios, acesso a informação e recursos tanto quanto estes estarão disponíveis". Além destes, tem o FCAT 2.0 - Teste de Ciências que é aplicado no quinto ano e oitavo ano do Ensino Fundamental. (FSA, 2015, tradução nossa).

O portal FSA providencia amplos recursos para treinamento dos estudantes, pais, professores, administradores dos testes, coordenadores de avaliação das escolas, coordenadores de avaliação dos municípios e coordenadores de tecnologia, tendo em vista que a partir deste último ano acadêmico os testes são realizados eletronicamente. Os recursos incluem: testes para treinamento, as habilidades esperadas para o teste ELA, especificação de itens dos testes com correspondente pontuação e pesos, orientações especificas de materiais para o teste de matemática como, por exemplo, calculadoras cientificas e planilhas.

Os testes para treinamento (sample tests) disponíveis no site do FSA podem ser realizados eletronicamente ou impressos e todos acompanham os gabaritos de respostas com explicações detalhadas sobre os itens que correspondem a respostas certas e erradas. Todos esses recursos, suportes, orientações, publicações, atividades modelos, vídeos, planos de aula para os professores (lesson plans), lições de estudo por ano escolar (toolkits), entre outros são disponibilizados pela agência parceira do Departamento de Educação da Florida chamada CPALMS ${ }^{4}$. CPLAMS is uma instituição não governamental que oficialmente serve ao Estado da Florida como "[...] fonte para padrões de informações e descrição de cursos e programas". É um sistema de "[...] caixa de ferramenta informacional online, recursos vetados e ferramentas interativas que ajudam efetivamente os professores a implementar padrões de ensino".

Este sistema operacional de informações fornece, atualmente, 518 planos de aula por meio da ferramenta chamada CPALMS Integrated STEM Lesson Development Program (Desenvolvimento de Programa de aulas integradas para STEM). Além dos planos de aula disponíveis no site, os professores podem participar de webinar, se desejarem. A base para este treinamento online ou conforme o CPALMS "desenvolvimento profissional" e a preparação de planos de aula com atividades interdisciplinares as quais envolvem STEM, visando crescimento profissional e aumento da compreensão dos padrões STEM. Os professores que aderirem aos webnars (Seminários on line) e cumprirem com a elaboração de três planos de aula conforme 
o modelo podem disponibilizá-los no CPALMS (nome do site/plataforma on line no qual os Webnars e materiais ficam disponíveis aos professores, alunos e pais) e receber estímulos financeiros por isso. (CPALMS, 2015). Cada plano de aula disponível nesta plataforma traz o código das habilidades que serão avaliadas nos testes. Além disso, os livros didáticos utilizados pelos professores nas escolas públicas do Estado da Florida também trazem esses códigos em cada capitulo de estudo e em cada disciplina. $\mathrm{Ou}$ seja, aparentemente, há um maciço processo de emparelhamento e padronização dos currículos, bem como, das práticas docentes escolares dado ao número de planos de aulas já prontos e disponíveis para acesso e uso destes pelos professores. Como desenvolver o senso crítico diante deste elevado nível de padronização dos kits de conteúdos e planos de ensino, respectivamente, para alunos e professores?.

\section{O Plano STEM e a Politica de Avaliação do Estado da Flóri- da: Relações, implicações e impactos}

Caracterizar as relações existentes entre a política estratégica para o desenvolvimento dos Estados Unidos (Plano STEM) e a política de avaliação para a Educação Básica no estado da Flórida é o interesse central deste trabalho. O que ficou evidente na projeção das intenções do Plano STEM (2013) e na política de avaliação do estado da Flórida, independentemente de juízo de valor que se possa fazer a esses referentes, é o fato de que a preocupação crítica em relação ao desenvolvimento, crescimento e controle econômico, político e social de uma Nação passam por seus níveis de qualidade educacional.

No entanto, as relações predominantes entre o plano STEM e a política de avaliação da Educação Básica do Estado da Flórida ficaram evidentes pelos termos: padronização, mensuração, treinamento, modelos, habilidades, áreas prioritárias, desempenho/progresso e desenvolvimento/crescimento profissional. Esses termos, embora tragam a ideia de progresso e de crescimento, no seu âmago representam valores da modernidade, principalmente no que tange a questões sobre: verdade, ciência e saber; ou melhor dizendo, a posição de quem sabe, dos responsáveis por estabelecerem as verdades a serem seguidas. Nesta linha, Foucault (1992, p. 12) explica que "o importante, creio, é que a verdade não existe fora do poder ou sem poder. [...] A verdade é deste mundo; ela é produzida nele graças a múltiplas coerções e nele produz efeitos regulamentados de poder".

Sendo assim, dado que o Plano STEM é deste mundo, da mesma forma é a política de avaliação do estado da Florida. O Plano STEM foi criado sob a ameaça da perda de poder e controle no futuro das nações. O texto do STEM adverte sobre as possíveis ameaças para seu futuro nas suas justificativas com base no seu histórico de proeminência de liderança e de controle. Em outras palavras, de poder sobre as demais nações e, por isso, este é um momento inadiável de sua história. Movimentos semelhantes, porém, aparentemente de menor alcance, dadas as proporções tecnológicas do atual momento, foram o lançamento do Satélite Russo "Sputnik" em 1957 e o The Nation at Risk de 1983, os quais resultaram em largos impactos nos currículos escolares, particularmente na área de ciências e matemática, além de amplos investimentos nas áreas associadas ao desenvolvimento profissional de modo a manter o controle e o poder na corrida por uma economia e uma política global. 
De acordo com Veiga-Neto (2012, p. 268), o que se expecta hoje, diante da famigerada rede de tecnologias e de informação, seriam outros aspectos como estratégicos para o desenvolvimento global e o pleno exercício da democracia. Por exemplo,

[...] a proclamada necessidade de uma educaçấo permanente; os imperativos contemporâneos da flexibilização (principalmente curricular) e da inclusão; a celebração da diferença; o esmaecimento do disciplinamento e das tecnologias disciplinares - com a simétrica ampliaçấo das práticas de controle [...].

No entanto, hão de se analisar as relações encontradas a partir de olhares por meio dos quais se alcance o desvelamento de suas entranhas, camadas e superfícies. As relações que enxergamos por meio dos termos padronização, mensuração, treinamento, modelos, habilidades, áreas prioritárias, desempenho/progresso e desenvolvimento/crescimento profissional, neste caso, é o de alinhamento, de nivelamento de valores, de imaginários e de verdades determinadas por interesses de alguém ou de determinados grupos (instituições parceiras, como expresso nos documentos) e que estão sendo legitimados pelo Estado.

Conforme Ball (2012), essas instituições parceiras funcionam sob a lógica do mercado ou do quasi-mercado. Isso implica dizer que as relações evidenciadas entre o STEM Americano e a política de avaliação da Educação Básica do estado da Florida são reflexos da agenda neoliberal que tem como foco a redução do Estado em detrimento de uma agenda estabelecida pelo mercado, mas que operam majoritariamente com recursos públicos e com as bênçãos do Estado. Portanto, essas relações têm como princípios fundantes alinhamento de metas, padronização de conteúdos, processos e procedimentos e performatividade porque o interesse fim é a redução de insumos e recursos, no entanto, com alta produtividade e lucratividade. Neste sentido, Ball (2010, p.38) explica que:

Performatividade é uma tecnologia, uma cultura e um modo de regulação, e mesmo, tal como define Lyotard, um sistema de "terror", sistema que implica julgamento, comparação e exposição, tomados respectivamente como formas de controle, de atrito e de mudança. [...] A questáo de quem controla o campo de julgamento é crucial. (Grifos do autor).

E isso não é bom, alguém poderá indagar? Se focarmos nosso olhar apenas para essa superfície, redução de custos, produtividade e lucratividade, poderíamos achar tudo isso bom. No entanto, há mais camadas que envolvem esta superfície, o que gera implicações e impactos improdutivos, particularmente sociais, emocionais e humanos. Por exemplo, na acepção de Ball (2010), os níveis de performatividade, de regulação e de controle sobre o quanto e como produzir, tem gerado ondas de terror nas instituições educacionais em todos os níveis e em outras organizações dado aos altos índices de performances individuais e institucionais que se vem estabelecendo. Outra implicação que se analisa é o fato de identificar quem determina os padrões, os procedimentos e os resultados esperados para o alcance destes índices de performatividades e para quem e por que essas metas são determinadas (professores? Alunos? etc). Além disso, quem se beneficia com esta forma de racionalidade nos processos de apropriação e produção de conhecimento pela educação? 
Além dessas implicações, há outras que afetam diretamente a definição dos currículos escolares, as práticas docentes e a formação dos estudantes. O nível de alinhamento e de padronização que percebemos impactam o currículo escolar no que se refere ao que deverá ser ensinado e com quais materiais (livros, ideologias, lógicas, e outros recursos) os estudantes serão ensinados. Adicionalmente, afetará a prática dos professores no que se refere ao como ensinar e para que ensinar determinados assuntos em detrimento de outros disponíveis e de outras formas de aprender e conhecer. E ainda, o que é mais critico é o fato de os estudantes serem treinados e dirigidos para este fim. Ou seja, por mais que os professores possam ter uma visão crítica deste modelo, os dispositivos utilizados, principalmente, pela massificação tecnológica, a partir de modelos de planos de aulas e outras toneladas de atividades prontas para os professores, kits para estudantes, testes para treinamento dos estudantes, orientações para pais e gestores, praticamente impõem as regras e as condutas para seguir o padrão.

Neste contexto, o currículo e a prática docente se constituem como dispositivos determinantes em direção a esta perspectiva ética e política na formação dos imaginários dos seus sujeitos cognoscentes. Particularmente na infância, as crianças tendem a incorporar os principais cânones que determinarão os sujeitos que se constituirão. Obviamente, nas outras etapas (adolescência e vida adulta) dos processos formativos escolares esses valores vão se consolidando e também, dependendo de seus contextos, podem se modificar.

No entanto, o padrão como este que está se impondo neste contexto neoliberal, o qual vem se incorporando de forma quase massificada em todas as instituições e modalidades educativas em âmbito mundial, poucas são as possibilidades de que este modelo não seja incorporado pelos imaginários dos estudantes. É praticamente assumir que as relações identitárias e lugares sociais de cada sujeito serão fortemente marcados pelo currículo e pelos processos de avaliação vivenciados na escola e pela prática docente exercida por seus professores e seus contextos escolares. Sendo assim, argumenta Ball (2010, p. 41):

[...] qualquer que seja nossa posição, nós agora operamos dentro de uma desconcertante imensidão de dados, indicadores de performance, comparações e competições de tal modo que a satisfação da estabilidade é cada vez mais fugidia, os propósitos são contraditórios, as motivações são borradas e a autoestima é escorregadia. Constantes dúvidas sobre quais julgamentos podem estar em jogo em qualquer altura significam que se deve prestar atenção a toda e qualquer comparação. O que é produzido é um estado de permanente e consciente visibilidade (ou visibilidades) na interseção do governo, da organização e da autoformação.

Diante disso, quem ganha e quem perde com este modelo de padronização massificada, baixos custos e alta produtividade? E o que acontece com aqueles que não atingem esses padrões? Esses podem ser estudantes, professores, gestores, entre outros. No caso dos professores, por mais que tentam planejar diferentemente, acabam tendo a sensação de culpa, de incapacidadee os estudantes a sensação e o estigma de fracasso. Em nosso olhar em perspectiva, a maior relação que se observa entre o Plano STEM e a política de avaliação do Estado da Flórida, neste caso em estudo, é a de aferição de 
padrões em relação às performances escolares e a classificação entre Gifteds (talentosos), regulares e fracassados. Consequentemente, "aqui então estão a culpa, a incerteza, a instabilidade e a emergência de uma nova subjetividade - um novo tipo de professor." (BALL, 2010, p. 40).

Eis aqui implicações e impactos imensuráveis que podem ser resultantes desta lógica: a de estabelecer prioridades e modelos para a educação, uma das principais alavancas para o desenvolvimento humano e científico de uma nação. Como formar um exército de professores "excelentes" conforme se explicita no Plano STEM (2013) ou 100.000 professores num período tão exíguo conforme prioriza este plano? Nos Estados Unidos, como resultado do programa No Child Left Behind - NCLB (nenhuma criança deixada para traz), se constituiu uma instituição filantrópica chamada Teach for America (TFA) in 1990 como uma alternativa para certificação de professores para a Educação Básica, dado a falta de professores para atuar em escolas públicas. Cinco semanas de treinamento intensivo dos recrutados lhes dá direito a certificação alternativa para que possam atuar como professores nas escolas para as quais forem designados. Enquanto nas universidades Americanas os cursos superiores voltados à formação de professores carecem de candidatos, TFA tem se tornado a maior instituição que prepara professores para atuar na Educação Básica na America. (RUSSO, 2012). Será esse o modelo que o Plano STEM vai adotar para atingir suas metas? Temos a sensação de este modelo já vem influenciando as políticas mundiais de formação de professores, particularmente no Brasil. O que pudemos inferir, a partir dessas análises, ainda que sucinta, é o fato de que este processo vem se construindo de modo que se consiga instituir um pensamento hegemônico nos modos de se fazer educação de "qualidade". Consequentemente, desse processo decorre uma sociedade mais produtiva e mais competente, pois o treinamento feito em cadeia no modelo ora analisado (atividades padronizadas para professores, gestores, estudantes e pais) se utiliza de estratégias tão racionalizadas e dirigidas as quais evidenciam uma intenção calculada de "emparelhamento" vinculado a uma lógica de mercado.

\section{Considerações finais}

Com base nos dados e nas análises realizadas em relação ao Plano STEM estadunidense e a política de avaliação do Estado da Flórida, que considerações e/ou preocupações temos para discutir? Uma das questões que consideramos crítica é a determinação somente das áreas das Ciências duras como prioritárias para o futuro do pais, conforme explicitado no documento. Embora haja alegação explícita no documento de que pesquisas vêm mostrando essa urgência e carência, nenhuma fonte de pesquisa de fato foi incluída no texto do documento. Nosso senso crítico atenta para o fato de que a atribuição de necessidades como resultantes de pesquisa que não apresenta indicação de fontes é no mínimo questionável. Para Ball $(2012,2010)$ essa agenda pode ser resultante de "fabricações" cujos interesses pertencem a grupos hegemônicos que lideram tanto na esfera pública quanto na esfera privada. A redução de custos, a alta produtividade e performance, bem como o consequente aumento de lucratividade a estes interessam. 
Outro aspecto que consideramos muito preocupante é o fato de que uma das prioridades estabelecidas no Plano STEM é a "melhora dos modelos de ensino". Associado a isto, notamos também que o CPALMS, instituição oficial online que serve ao Estado da Florida em relação a sua política de avaliação, disponibiliza planos de aula vinculados aos códigos das habilidades que se pretende avaliar no desempenho dos estudantes. Isso significa que, além de determinarem dessa maneira, os currículos escolares, estão partindo do pressuposto de que os professores não precisam saber ou pensar, basta-lhes que sigam modelos. Eis aí o sucesso da instituição Teach For America! Seria isso uma tendência para uma agenda mundial? Obviamente, este artigo é apenas um recorte de uma pesquisa maior que estamos conduzindo. Por isso, consideramos também que pesquisas ampliadas poderão ser apropriadas para este objeto.

Por fim, ousamos levantar a tese de que este objeto de pesquisa faz parte de uma agenda neoliberal global cujos interesses econômicos e políticos vêm para cumprir interesses construídos por líderes e especuladores mundiais os quais visam massificar ideologias, projetos, processos, procedimentos e resultados em todas as áreas em esfera global. Ousamos ainda mais em dizer que, no contexto dessa agenda e deste jogo global, a educação terá papel estratégico e determinante, pois funcionará como ferramenta principal na formação de imaginários característicos deste modelo em todas as áreas do conhecimento. No caso do Brasil, o Ministério da Educação já vem trabalhando na construção de um projeto curricular de base comum para a Educação Básica o qual deverá ser executado por escolas públicas e privada. O argumento vem sendo os indicadores de aprendizagem distintos observados nas diferentes regiões e municípios do país sinalizados pelas políticas de avaliação em larga escala como: Provinha Brasil, Prova Brasil, ANA e ENEM. Acreditamos que esse movimento em direção de um currículo com base nacional comum já representa um impacto relacionado com políticas internacionais mais amplas como, por exemplo, o Plano STEM dos Estados Unidos.

\section{Referências}

CARDOSO, S. O olhar viajante (do etnólogo). In: O olhar. São Paulo: Companhia das letras, 1988.

BALL, J. S. Performatividades e fabricaçôes na economia educacional: rumo a uma sociedade performativa. Educaçăo e Realidade. v. 35, n. 2, p. 37-55, 2010

CHAUÍ, M. Janela da alma, espelho do mundo. In: NOVAES, A. et al. O olhar. São Paulo: Companhia das letras, 1988.

EXECUTIVE OFFICE OF THE PRESIDENT OF THE UNITED STATES. Federal Science, Technology, Engineering, and Mathematics (STEM) Education: 5-Year Strategic Plan. A Report from the Committee on STEM Education National Science and Technology Council. May, 2013. Disponivel em: <https://www.whitehouse.gov/sites/default/files/microsites/ostp/stem_stratplan_2013.pdf>. Acesso em: 27 nov. 2014.

FLORIDA DEPARTMENT OF EDUCATION. Florida Standarts Assessment. Disponível em: <http://fldoe.org/accoutability/assessments/k-12-students-assessments/fsa.stml>. Acesso em: 22 maio 2015.

FOUCAULT, M. Microfísica do poder. Rio de janeiro: Graal, 1992. 
MERLEAU-PONTY, M. O visível e o invisível. São Paulo: Perspectivas, 2007.

RUSSO, A. Left Out no Child Left Behind: Teach for America's outsized influence on alternative certification. American enterprise institute: Future of american Education Project series. Washington, D.C., 2012.

SANTOS, S. B. Parceria público-privadas e justiça. Uma análise comparada de diferentes experiências. Relatório do observatório permanente da justiça portuguesa. Centro de Estudos Sociais. Universidade de Coimbra. 2007. Disponível em: <http://opj.ces.uc.pt/pdf/rel_parcerias_publico_ privadas_justica.pdf>. Acesso em: 6 dez. 2012.

SANTOS, V. M. dos. Políticas Públicas em Educação: a "lógica subalternizante” vigente na América Latina e seus reflexos na universidade brasileira. Emancipaçáo, Ponta Grossa, 8(1): p. 79-93, 2008.

SPOSATI, A. Tendências latino-americanas da política social pública no século 21. Revista Katál, Florianópolis, v. 14, n. 1, p. 104-115, jan./jun., 2011

SERRES, M. Diálogo sobre a ciência, a cultura e o tempo. Lisboa: Instituto Piaget, 1996.

BALL, J. S. Global Education Inc.: New Policy Networks and Neo-liberal Imaginary. Routledge, 2012.

VEIGA-NETO, A. É preciso ir aos poróes. Revista Brasileira de Educaçáo v. 17 n. 50 maio-ago. 2012, p. 267-492.

UNESCO. Declaraçáo mundial sobre Educaçáo para todos e plano para satisfazer às necessidades básicas de aprendizagem. Aprovada pela conferência Mundial sobre educação para todos e satisfação das necessidades básicas de aprendizagem, Jontiem, Tailândia, 1990.

\section{Notas}

\footnotetext{
${ }^{1}$ Federal Science, Technology, Engineering, and Mathematics (STEM) Education: 5-Year strategic plan: e um plano estratégico Federal de metas elaborado por vários comitês e coordenados pelo Conselho Executivo da Presidência da Republica dos Estados Unidos e publicado em maio de 2013. O documento contem 50 paginas com detalhamento em cinco capítulos e dois apêndices os quais somam 116 paginas ao documento, no total. O documento complete e informaçōes adicionais podem ser encontrados online no site: http://www.ostp.gov.

${ }^{2}$ Os documentos oficiais que explicitam a politica de avaliação educacional do Estado da Florida, USA, o Florida Standards Assessments, além de informaçôes adicionais sobre seus processos de implantação e orientaçôes para professores, gestores, estudantes e famílias estão disponíveis online pelo site: http://www.fldoe.org/accoutability/assessments/k-12/fsa.stml.

${ }^{3}$ Significa desdobramento de olhares a partir de um lugar exterior. Etimologicamente a palavra exotopia é formada pelo prefixo "ex" que significa fora e "topos" que significa lugar. Olhar externo.

${ }^{4}$ Todas as informaçốes online providas pela CPALMS ao Estado da Florida podem ser acessadas pelo site: http:// www.cpalms.org/public/.
}

*Financiamento CAPES 
Educação para Ciência, Tecnologia, Engenharia e Matemática e as Relações com a Politica de Avaliação em Larga Escala na Educação Básica

** Professora doutora da Universidade do Vale do Itajaí, Itajaí, Santa Catarina, Brasil.

*** Professora doutora da Barry University, Miami, Florida, EUA.

\section{Correspondência}

Veronica Gesser - Universidade do Vale do Itajaí, Pró Reitoria de Ensino. Rua Uruguai, 458, Centro, CEP: 88302-202 0 Itajai, Santa Catarina - Brasil - Caixa-postal: 360.

E-mail: gesserv@univali.br - 1dibello@barry.edu

Recebido em 29 de maio de 2015

Aprovado em 03 de dezembro de 2015 
